\section{Effectiveness of alkaline electrolyzed water in reducing bacterial load on surfaces intended to come into contact with food}

\author{
Federico Tomasello, ${ }^{1}$ Marta Pollesel, ${ }^{1}$ \\ Elisabetta Mondo, ${ }^{1}$ Federica Savini, ${ }^{1}$ \\ Raffaele Scarpellini, ${ }^{1}$ Federica \\ Giacometti, ${ }^{1}$ Luna Lorito, ${ }^{1}$ \\ Marco Tassinari, ${ }^{1}$ Sean Cuomo, ${ }^{2}$ \\ Silvia Piva, ${ }^{1}$ Andrea Serraino ${ }^{1}$ \\ ${ }^{1}$ Department of Veterinary Medical \\ Sciences, University of Bologna, Ozzano \\ dell'Emilia (BO); ${ }^{2}$ Arredo inox S.r.l., \\ Crotone, Italy
}

\begin{abstract}
Alkaline electrolyzed water (REW) is known for its cleaning action. The aim of this work was to assess REW effectiveness in reducing microbial load on surfaces intended for contact with food. Stainlesssteel surfaces were experimentally contaminated, bacterial inactivation was tested before and after treatment with REW. Treatment with REW was operated spraying it on the contaminated plates until drying. Tests were conducted for Salmonella spp., Listeria spp., Staphylococcus aureus and Escherichia coli. The treatment revealed different degrees of sanitizing activity of REW on different bacterial species, with higher efficacy on $E$. coli and Salmonella spp. than $S$. aureus, Listeria spp.. Statistical analysis revealed a significant microbial load reduction $(\mathrm{p}<0.01)$ after treatment with REW, suggesting that it has a good disinfectant activity which, along with its easy and safe use, makes it a good alternative to many other more widely used disinfectants.
\end{abstract}

\section{Introduction}

Foodborne pathogens are currently estimated to be responsible for one third of human diseases in the developed world. In Europe during 2019, 27 Member States reported 5,175 food-borne outbreaks involving 49,463 cases of illness, 3,859 hospitalizations and 60 deaths: $45.7 \%$ were caused by bacteria and bacterial toxins and mainly linked to consumption of food of animal origin (EFSA and ECDC, 2021).

Although animals and humans are a major source of bacterial food contamina- tion, in the food industry, products are often biologically contaminated through contact with the surfaces of equipment, shredders, slicers, and cutting boards (Fukuzaki et al., 2004; Serraino et al., 2010). Procedures aiming at reducing or even eliminating pathogens from surfaces are one of the key points of an effective HACCP program in the food industry and also in controlling food contamination in homes, food markets, restaurants, health facilities and public areas (Venkitanarayanan et al., 1999).

Recently, electrolyzed water (EW) has been receiving attention as a novel disinfectant and cleaning solution. Electrolyzed water is obtained from the electrolysis of a salt solution, generally $\mathrm{NaCl}(\approx 2 \mathrm{~g} / \mathrm{L})$. When electricity flows through the solution two types of water are generated: the cathode produces alkaline electrolyzed water (REW) containing sodium hydroxide ( $\mathrm{pH}$ 11.6; ORP $\approx-795 \mathrm{mV}$ ), while the anode produces acidic electrolyzed water (EOW) containing hypochlorous acid $(\mathrm{pH}$ 2.4-2.7; $\mathrm{ORP} \approx 1150 \mathrm{mV}$ ); the concentration of the residual chlorine depends on the EW machine setting (Fukuzaki et al., 2004).

As a potent yet safe-to-handle sanitizer, the EOW has been easily applied into various industries, as disinfectant for food processing equipment either on various materials (stainless steel, glass) (Park et al., 2002; Serraino et al., 2010), or directly on food (vegetables, poultry, eggs, fish) (Athayde $e t$ al., 2018; Fabrizio et al., 2002; Huang et al., 2008). The REW has not seen as widespread use as EOW and has been mainly considered a waste, but some research have demonstrated that it can be employed in different manners within the food industry, in particular as a cleaning solution; moreover it has been demonstrated that the combined use of REW and EOW enhances the microbial load reduction (Athayde et al., 2018; Fukuzaki et al., 2004; Huang et al., 2008). The aim of this work was to evaluate the efficacy of the REW in reducing the microbial load on experimentally contaminated stainless-steel surfaces intended for contact with food, to define its possible use in operating conditions as a sanitizer as well as a detergent of surfaces.

\section{Materials and methods}

Alkaline electrolyzed water (REW) was obtained from Aquasol S.r.l (Bologna, Italy), generated through an electrochemical process that uses reverse osmosis water and potassium carbonate $\left(\mathrm{K}_{2} \mathrm{CO}_{3}\right)$ as electrolyte. REW is made up of $99.83 \%$ pure water and $0.17 \%$ of potassium hydroxide $(\mathrm{KOH})$ with a $\mathrm{pH}$ of $12.2-12.5$ and an oxi-
Correspondence: Federico Tomasello, Department of Veterinary Medical Sciences University of Bologna, Via Tolara di Sopra $n$. 50, 40064 Ozzano dell'Emilia (BO), Italy.

E-mail: federico.tomasello4@unibo.it

Key words: Alkaline electrolyzed water, Bacterial inactivation, Food, Surfaces, Foodborne pathogens.

Contributions: The authors contributed equally.

Conflict of interest: The authors declare no conflict of interest.

Funding: None.

Availability of data and materials: All data and materials are available within the text.

Received for publication: 22 July 2021 .

Revision received: 20 September 2021.

Accepted for publication: 21 September 2021

This work is licensed under a Creative Commons Attribution-NonCommercial 4.0 International License (CC BY-NC 4.0).

(C) Copyright: the Author(s), 2021

Licensee PAGEPress, Italy

Italian Journal of Food Safety 2021; 10:9988

doi:10.4081/ijfs.2021.9988

dation - reduction potential of $-40 /-90 \mathrm{mV}$. Chemical characteristics, like $\mathrm{pH}$ and oxidation-reduction potential (ORP), were measured with a pH-meter (FiveGo F2, Mettler - Toledo, Greifensee, Switzerland), using LE427 and LE510 electrodes to measure $\mathrm{pH}$ and ORP, respectively.

Four tests were performed to evaluate the disinfectant activity on Salmonella spp., Listeria spp., Staphylococcus aureus and Escherichia coli.

A mix of three different strains was used for each test (Table 1), strains were selected including one reference strain and two strains isolated from animal production chains.

For each test eight stainless steel plates were used, representing eight repetitions for each bacterial species: an area of $100 \mathrm{~cm}^{2}$ was defined on the plates previously sterilized. Each plate was contaminated with a $10^{11} \mathrm{UFC} / \mathrm{ml}$ suspension of the above-mentioned microorganisms, using a sterile swab, to a total of about $10^{4} \mathrm{UFC} / \mathrm{cm}^{2}$ in the plate. The $100 \mathrm{~cm}^{2}$ area was divided by two and, after drying, half of the plate was sampled with a sterile sponge, to evaluate the pre-treatment microbial load. REW was then applied with a low-pressure pump, left to dry for about 15 minutes and the second half of the plate was sampled through sterile sponge, to evaluate the microbial load after 
treatment. In detail, sterile sponges were rubbed over the previously described areas 10 times and then put in a sterile plastic bag containing $100 \mathrm{~mL}$ of sterile saline solution. After mixing in a stomacher (BagMixer ${ }^{\circledR}$, Interscience, St Nom, France) $0.1 \mathrm{~mL}$ of the sample obtained and $0.1 \mathrm{~mL}$ of four serial 10 -fold dilutions were seeded in plastic Petri dishes containing PCA and incubated at $37^{\circ} \mathrm{C}$ for $24 \mathrm{~h}$. After incubation, colonies were identified with matrix-assisted laser desorption/ionizationtime-of-flight (MALDI-TOF, Bruker, Massachusetts, USA) and then counted.

Results were expressed as $\log$ $\mathrm{UFC} / \mathrm{cm}^{2}$, and statistical analysis was made by paired T-test, one-way ANOVA and Tukey post-hoc test $(\mathrm{p} \leq 0.01)$.

\section{Results}

Treatment of artificially contaminated surfaces with REW revealed different degrees of microbial load reduction in different tests.

Overall, a $2.64 \quad( \pm 1.52$ SD) $\log$ $\mathrm{UFC} / \mathrm{cm}^{2}$ reduction was observed, resulting in a significant $(\mathrm{p}<0.01)$ microbial reduction. A minimum of $0.43 \mathrm{log} \mathrm{UFC} / \mathrm{cm}^{2}$ in one out of the eight tests for $S$. aureus and a maximum of $5.63 \mathrm{log} \mathrm{UFC} / \mathrm{cm}^{2}$ in one of the eight tests for Salmonella spp.. In detail Salmonella spp. was reduced by $3.70( \pm 1.35$ SD) $\log \mathrm{UFC} / \mathrm{cm}^{2}$, E. coli by $3.29( \pm 1.35$
SD) $\log \mathrm{UFC} / \mathrm{cm}^{2}$, Listeria spp. by 2.41 $( \pm 1.22 \mathrm{SD}) \log \mathrm{UFC} / \mathrm{cm}^{2}, S$. aureus by 1.16 $( \pm 0.90 \mathrm{SD}) \log \mathrm{UFC} / \mathrm{cm}^{2}$ on average. Details of the results are reported in Table 2 and Figure 1.

\section{Discussion}

REW is well known as detergent, dissolving fats and proteins. Some authors have suggested that using REW as pre-treatment before using disinfectants might enhance the action of the latter (Ayebah et al., 2005; Fabrizio et al., 2002; JiménezPichardo et al., 2016), therefore the cleaning action of REW could improve its disinfectant efficacy by removing organic mate- rial that could shelter microorganisms.

In this work, treatment with REW led to a significant $(p<0.01)$ overall reduction of microbial load compared to the pre-treatment samples. Results showed different degrees of microbial load reduction on different bacterial species. Specifically, REW showed to be significantly $(\mathrm{p}<0.01)$ effective on Salmonella spp., E. coli, S. aureus and Listeria spp.. Moreover, it appeared to be significantly $(\mathrm{p}<0.01)$ more effective on Gram negative bacteria (Salmonella spp., and $E$. coli), with an average microbial reduction of $3.49( \pm 1.31 \mathrm{SD}) \log \mathrm{UFC} / \mathrm{cm}^{2}$ and a high occurrence (75\%) of no microbial growth after treatment, being instead less effective on gram positive microorgan-

Table 1. Bacterial strains used and their biological matrices of origin.

\begin{tabular}{lll}
\hline Microorganism species & Strain & Biological matrices of origin \\
Escherichia coli & ATCC 25922 & \\
Escherichia coli & VeLaBac 444 & Bovine faeces \\
\hline Escherichia coli & VeLaBac 445 & Meat \\
Salmonella Thyphimurium & ATCC 14020 & \\
\hline Salmonella Thyphimurium monophasic & $118174 / 1$ & Pork sausage \\
Salmonella Derby & $106463 / 1$ & Pork meat \\
\hline Listeria monocytogenes & ATCC 15313 & \\
Listeria innocua & $257529 / 1$ & Pork sausage \\
\hline Listeria innocua & $257529 / 2$ & Pork meat \\
Staphylococcus aureus & ATCC 25923 & \\
\hline Staphylococcus aureus & B/122/2 & Raw milk \\
Staphylococcus aureus & $22-7-16 / 2$ & Goat skin
\end{tabular}
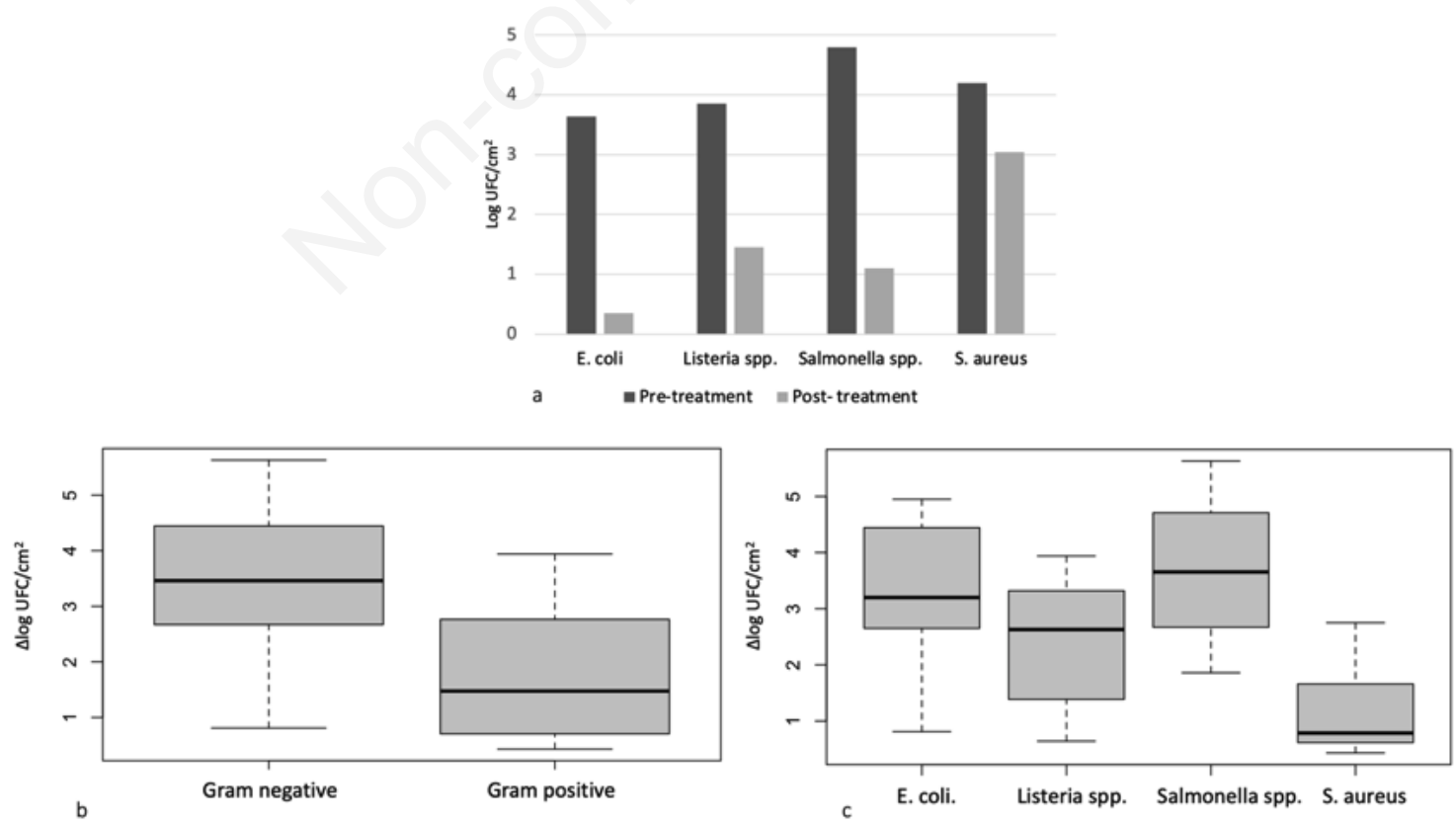

Figure 1. a) Mean Bacterial counts before and after treatment with REW for each microorganism and mean microbial load reduction values $\left(\triangle \log \mathrm{UFC} / \mathrm{cm}^{2}\right)$ for $\left.\mathrm{b}\right)$ gram-negative and gram-positive bacteria, and c) each microorganism. 
Table 2. Bacterial counts before and after treatment with REW, and microbial reduction expressed as mean $( \pm \mathrm{SD})$, minimum and maximum $\left(\Delta \log \mathrm{UFC} / \mathrm{cm}^{2}\right)$.

\begin{tabular}{|c|c|c|c|c|c|}
\hline Microorganism & $\begin{array}{l}\text { Pre - treatment } \\
\text { Log UFC/ } \mathrm{cm}^{2} \\
\text { mean }( \pm \mathrm{SD})\end{array}$ & $\begin{array}{l}\text { Post- treatment } \\
\mathrm{Log} \mathrm{UFC} / \mathrm{cm}^{2} \\
\text { mean }( \pm \mathrm{SD})\end{array}$ & $\begin{array}{c}\text { Microbial reduction } \\
\varnothing \mathrm{Log} \mathrm{UFC} / \mathrm{cm}^{2} \\
\text { mean }( \pm \mathrm{SD})\end{array}$ & $\begin{array}{c}\text { Minimum microbial } \\
\text { reduction } \\
\Delta \log \mathrm{UFC} / \mathrm{cm}^{2}\end{array}$ & $\begin{array}{c}\text { Maximum microbial } \\
\text { reduction } \\
\Delta \mathrm{Log} \mathrm{UFC} / \mathrm{cm}^{2}\end{array}$ \\
\hline Escherichia coli & $3.64( \pm 0.79)$ & $0.35( \pm 0.98)$ & $3.29( \pm 1.35)$ & 0.81 & 4.95 \\
\hline Salmonella spp. & $4.80( \pm 1.29)$ & $1.10( \pm 1.58)$ & $3.70( \pm 1.35)$ & 1.86 & 5.63 \\
\hline Listeria spp. & $3.85( \pm 0.49)$ & $1.45( \pm 1.61)$ & $2.41( \pm 1.22)$ & 0.64 & 3.94 \\
\hline Staphylococcus aureus & $4.20( \pm 0.20)$ & $3.04( \pm 0.90)$ & $1.16( \pm 0.90)$ & 0.43 & 2.75 \\
\hline
\end{tabular}

isms (S. aureus and Listeria spp.) with an average microbial reduction of $1.78( \pm 1.21$ $\mathrm{SD}) \log \mathrm{UFC} / \mathrm{cm}^{2}$. There's large evidence in literature of the major resistance of Gram positive bacteria to sanitizing treatments than Gram negative bacteria, and being the major difference between the two groups the thickness of the cell wall, responsible for preserving the integrity of the cell, also the results of this work suggest that the wall thickness may play a role in the REW bacterial inactivation efficacy (Koike et al., 2009; Mai-Prochnow et al., 2016; Vollmer et al., 2008).

Other authors found similar results when testing slightly acidic electrolyzed water (SAEW) and strongly alkaline electrolyzed water, with Gram positive bacteria showing relatively more resistance to the treatment than Gram negative bacteria (Issa-Zacharia et al., 2010; Koike et al., 2009; Tango et al., 2015). In addition, different microorganisms may have different sensibility to sanitizers, for example Listeria spp. is generally more resistant to chlorine than Salmonella spp. and E. coli (Burnett \& Beuchat, 2000).

In literature no other work evaluated the efficacy of REW alone in reducing the microbial load on stainless steel surfaces; other authors evaluated its efficacy in association with SAEW and ultrasound to improve the sanitation of knives in the meat industry, but due to the different treatments applied we could not compare the data (Brasil et al., 2020).

It is important to notice that the tests underwent microbial load conditions that are not the ones typical of working conditions. Indeed, contamination levels in the food industry are usually much lower than those considered in this work, especially considering pathogenic microorganisms. In addition, in this work it was considered just the REW action, while in operating conditions it could be associated to a mechanical bacterial removal action, that could make the treatment even more effective.

Economically REW is not competitive with the most common commercial sanitiz- ers, yet, besides its efficacy as detergent and disinfectant, REW is safe to handle, bearing no risks for the users and has low environmental impact, being composed by $99.83 \%$ pure water and $0.17 \%$ of potassium hydroxide $(\mathrm{KOH})$ and not containing environmental pollutants, moreover, its instability makes unnecessary to rinse surfaces with water after its use and hence saving time during working activities (Athayde et al., 2018; Fabrizio et al., 2002; Huang et al., 2008). All this makes REW a suitable alternative to the most common commercial formulation for use in some particular productions process.

\section{Conclusions}

The results of this study showed its efficacy in reducing the microbial load on stainless-steel surfaces under experimental conditions, giving a good perspective on its use as sanitizing under operative conditions on surfaces intended for contact with food.

\section{References}

Athayde DR, Flores DRM, Silva JS, Silva MS, Genro ALG, Wagner R, Campagnol PCB, Menezes CR, Cichoski AJ, 2018. Characteristics and use of electrolyzed water in food industries. Int Food Res J 25:11-6.

Ayebah B, Hung YC, Frank JF, 2005. Enhancing the Bactericidal Effect of Electrolyzed Water on Listeria monocytogenes Biofilms Formed on Stainless Steel. J Food Protect 68:1375-80.

Brasil CCB, de Menezes CR, Jacob $\square$ Lopes E, Barin JS, Zepka LQ, Campagnol PCB, Wagner R, Cichoski AJ, 2020. Combined application of electrolysed water and ultrasound to improve the sanitation of knives in the meat industry. Int J Food Sci Technol 55:1136-44.

Burnett SL, Beuchat LR, 2000. Human pathogens associated with raw produce and unpasteurized juices, and difficulties in decontamination. J Industr Microbiol Biotechnol 25:281-7.

EFSA and ECDC (European Food Safety Authority and European Centre for Disease Prevention and, \& Control). (2021). The European Union One Health 2019 Zoonoses Report. In EFSA J 19:6406.

Fabrizio K, Sharma R, Demirci A, Cutter C, 2002. Comparison of electrolyzed oxidizing water with various antimicrobial interventions to reduce Salmonella species on poultry. Poultry Sci $81: 1598$ 605.

Fukuzaki S, Hiratsuka H, Takehara A, Takahashi K, Sasaki K, 2004. Efficacy of electrolyzed water as a primary cleaning agent. Biocontrol Sci 9:105-9.

Huang YR, Hung YC, Hsu SY, Huang YW, Hwang DF, 2008. Application of electrolyzed water in the food industry. Food Control 19:329-45.

Issa-Zacharia A, Kamitani Y, Morita K, Iwasaki K, 2010. Sanitization potency of slightly acidic electrolyzed water against pure cultures of Escherichia coli and Staphylococcus aureus, in comparison with that of other food sanitizers. Food Control 21:740-5.

Jiménez-Pichardo R, Regalado C, CastañoTostado E, Meas-Vong Y, Santos-Cruz J, García-Almendárez BE, 2016. Evaluation of electrolyzed water as cleaning and disinfection agent on stainless steel as a model surface in the dairy industry. Food Control 60:320-8.

Koike M, Kitamura T, Todo H, Tokudome Y, Hashimoto F, Isshiki Y, Kondo S, Sugibayashi K, 2009. Bactericidal Activities of Several Electrolyzed Waters. J Soc Cosmetic Chem Japan 43:101-6.

Mai-Prochnow A, Clauson M, Hong J, Murphy AB, 2016. Gram positive and Gram negative bacteria differ in their sensitivity to cold plasma. Sci Rep 6:38610.

Park H, Hung YC, Kim C, 2002. Effectiveness of Electrolyzed Water as a 
Sanitizer for Treating Different Surfaces. J Food Protect 65:1276-80.

Serraino A, Veronese G, Alonso S, Matera R, Lugoboni B, Giacometti F, 2010. Bactericidal activity of electrolyzed oxidizing water on food processing surfaces. Ital J Food Sci 22:222-8.

Tango C, Mansur A, Oh DH, 2015. Fumaric
Acid and Slightly Acidic Electrolyzed Water Inactivate Gram Positive and Gram Negative Foodborne Pathogens. Microorganisms 3:34-46.

Venkitanarayanan KS, Ezeike GO, Hung YC, Doyle MP, 1999. Efficacy of Electrolyzed Oxidizing Water for Inactivating Escherichia coli O157:H7,
Salmonella enteritidis, and Listeria monocytogenes. Appl Environ Microbiol 65:4276-9.

Vollmer W, Blanot D, De Pedro MA, 2008. Peptidoglycan structure and architecture. FEMS Microbiol Rev 32:149-67. 